\title{
Structural, Morphological and Optical Properties of Aluminium Doped ZnO Thin Film by Dip-Coating Method
}

\author{
BA. ANANDH ${ }^{1 *}$, A. SHANKAR GANESH ${ }^{1}$, R. THANGARASU ${ }^{2}$, R.SAKTHIVEL $^{3}$, \\ R. KANNUSAMY ${ }^{4}$ and K. TAMILSELVAN ${ }^{5}$
}

1,3,485 Department of Electronics, PSG College of Arts \& Science, Coimbatore-14, India.

2Department of Physics, PSG College of Arts \& Science, Coimbatore-14, India.

${ }^{*}$ Corresponding author E-mail: anandh.ba@gmail.com

http://dx.doi.org/10.13005/ojc/340356

(Received: January 23, 2018; Accepted: May 18, 2018)

\begin{abstract}
Dip coating method is used for depositing Aluminium (Al) doped Zinc Oxide ( $\mathrm{ZnO})$ thin films on glass substrate. Undoped, 1\%, 3\% and 5\% Al doped $\mathrm{ZnO}$ thin films are prepared and their structural, morphological and optical properties are studied. X-ray diffraction study confirms that films are polycrystalline with hexagonal arrangement. Field Emission Scanning Electron Microscope (FESEM) is used to analyze the surface morphology and it shows the spherical like structure. Energy Dispersive X-ray Analysis (EDX) pattern shows the presence of Zn, O and AI. UV-Vis. Spectroscopy and Photoluminescence spectroscopy (PLS) are used to study optical properties. Optical study indicates that both undoped and Aluminium doped $\mathrm{ZnO}$ films are transparent in UV region and closer to visible region. The band gaps of the films are $3.55 \mathrm{eV}, 3.68 \mathrm{eV}, 3.82 \mathrm{eV}$ and $3.25 \mathrm{eV}$ for undoped, $1 \%, 3 \%$ and $5 \%$ Aluminium doped $\mathrm{ZnO}$ films correspondingly.
\end{abstract}

Keywords: Thin film, Aluminium doped ZnO, Dip coating, X-ray diffraction (XRD), Field Emission
Scanning Electron Microscope (FESEM), UV-Vis. Spectroscopy (UV), Photoluminescence spectroscopy (PL).

\section{INTRODUCTION}

Transparent conductive oxide (TCO) materials have many applications in the area of displays, photovoltaic devices and LED's ${ }^{1-3}$. Zinc oxide has extensive band gap $(3.37 \mathrm{eV})$ at room temperature, good chemical stability, excellent thermal stability and high exciting binding energy $(60 \mathrm{meV})^{4}$. $\mathrm{ZnO}$ thin films have many advantages such as non-toxic, low cost, good electrical and optical properties with very high electrical resistivity ${ }^{5}$. The properties of $\mathrm{ZnO}$ films can be improved by doping any one of the group III element. Aluminium is one of the group III element which is mainly doped with $\mathrm{ZnO}$ to obtain good stability and low resistivity ${ }^{6}$.

Many methods were used to obtain $\mathrm{ZnO}$ thin films such as chemical bath deposition ${ }^{7}$, dip coating method $^{8}$, thermal vacuum evaporation 
method $^{9}$, sol-gel method ${ }^{10}$, hydrothermal method ${ }^{11}$, magnetron sputtering ${ }^{12}$, oxygen plasma assisted molecular beam epitaxy ${ }^{13}$, laser coating and several other methods. Dip coating method is simple, inexpensive and gives uniform thin films.

The aim of the present work is to study the effect of aluminium doping on structural, morphological and optical properties of $\mathrm{ZnO}$ thin films.

\section{EXPERIMENTAL PROCEDURE}

\section{Cleaning of glass substrate}

The glass substrates for depositing the films are initially cleaned with detergent, DI water and acetone. Nitric acid and DI water are used for secondary cleaning process and finally the glass substrates are cleaned in ultrasonic bath using acetone and dried for 10 minutes in hot air oven.

\section{Deposition of undoped $\mathrm{ZnO}$ and Aluminium (Al) doped $\mathrm{ZnO}$ thin films.}

Zinc acetate dehydrate (ZAD) is used as base material. Ethanol and Monoethanolamine were used as solvent and stabilizer respectively. The zincate bath was prepared by dissolving ZAD in $100 \mathrm{ml}$ of ethanol and stirred for $2 \mathrm{~h}$, using magnetic stirrer and left covered for 24 hours. Molar ratio between ZAD and MEA is kept at $0.1 \mathrm{M}$. The undoped $\mathrm{ZnO}$ film is prepared by alternatively dipping the precleaned glass substrate into zincate and hot $\mathrm{DI}$ water baths for $30 \mathrm{sec}$ each and the dipping process is repeated for 30 cycles.

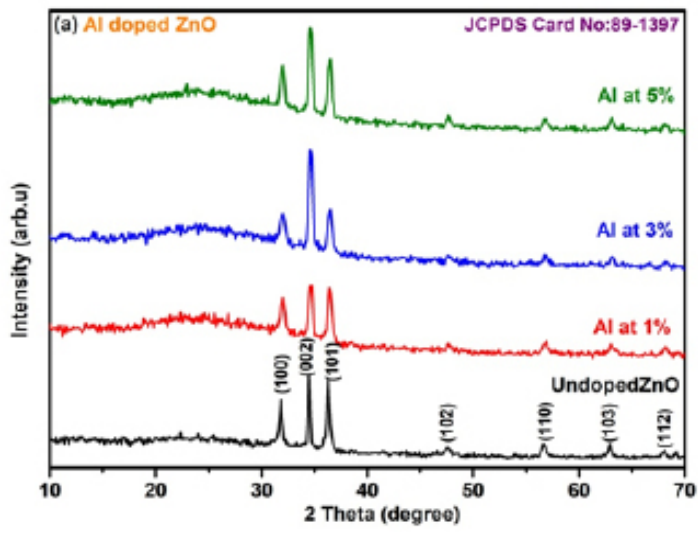

Aluminium acetate is used for doping aluminium and is added along with ZAD in $100 \mathrm{ml}$ of ethanol and is stirred for $2 \mathrm{~h}$, in magnetic stirrer and kept covered for 24 hours. The solutions are prepared for $1 \%, 3 \%$ and $5 \% \mathrm{Al}$ content. Al doped $\mathrm{ZnO}$ films are formed by alternately dipping the pre-cleaned microscopic glass substrate in Al dissolved zincate bath and hot DI water bath for 30 sec each and the dipping process is repeated for 30 cycles. The $\mathrm{ZnO}$ films are prepared for undoped, $1 \%, 3 \%$ and $5 \% \mathrm{Al}$ content and post annealed at $350^{\circ} \mathrm{C}$.

\section{RESULTS AND DISCUSSION}

\section{Structural Studies}

Figure. 1(a) represents XRD of undoped, $1 \%, 3 \%$, and $5 \%$ Al concentrations of $\mathrm{ZnO}$ films, post annealed at $350^{\circ} \mathrm{C}$. The peaks appeared in the XRD pattern shows the Wurtzite hexagonal form of $\mathrm{ZnO}$ (JCPDS card: 89-1397). The orientation of peak at (002) plane shows the polycrystalline nature, other XRD peaks appear at (100), (101), (102), (110), (103) and (112) planes. Fig.1 (b) shows change in lower diffraction angle $\left(33.5^{\circ}\right.$ to $\left.33.5^{\circ}\right)$ for different peaks owing to the $\mathrm{Al}$ concentration. The intensity of the peak in the (002) plane of undoped and $\mathrm{Al}$ doped $\mathrm{ZnO}$ shows decreased crystal size. The XRD indicates only $\mathrm{ZnO}$ peaks and no peaks related to aluminium and its components. The reason may be presence of a small amount of aluminium content in the form of very small cluster in the $\mathrm{ZnO}$ lattice, so it may be very hard to detect by XRD instrument and it may present in the grain boundaries of the $\mathrm{ZnO}$ nano crystals or distributed atomically within the $\mathrm{ZnO}$ lattice.

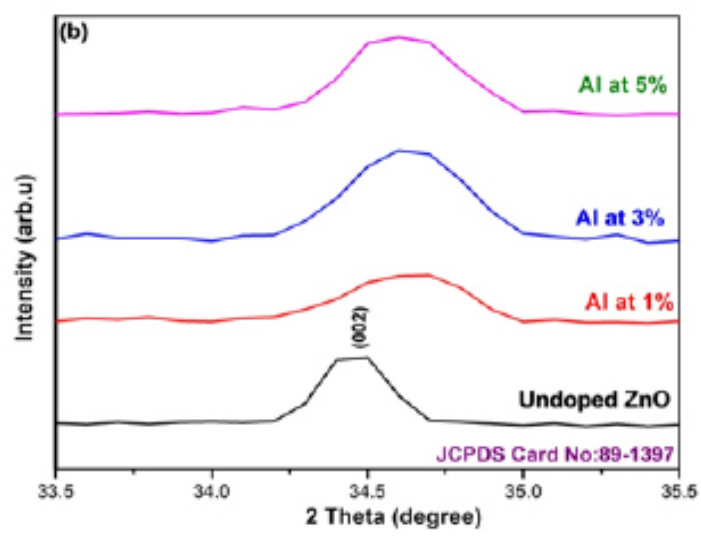

Fig. 1. (a) XRD of undoped and Al doped ZnO Thin Films (b) The shift position in the diffraction angles at (002) peaks 
Debye-Scherrer's formula ${ }^{14}$ is used to calculate the crystalline size of the prepared films.

$$
D=\frac{0.89 \lambda}{\beta \cos \theta}
$$

The dislocation density $(\delta)$ is calculated using equation 2 , and micro strain $(\varepsilon)$ values is calculated using equation $3^{15}$

$$
\begin{gathered}
\delta=\frac{1}{D^{2}} \\
\varepsilon=\frac{\beta \cos \theta}{4}
\end{gathered}
$$

Where $D$ indicates crystalline size, $\lambda$ for the wavelength, $\beta$ for the FWHM and $\theta$ is the diffraction angle in degrees ${ }^{16}$. Table: 1 indicates that the average crystalline size (D) for undoped $\mathrm{ZnO}$ is $31.32 \mathrm{~nm}$ and it decreases to $16.30 \mathrm{~nm}$ for $1 \% \mathrm{Al}$ and $18.66 \mathrm{~nm}$ for $3 \%$ Al and $19.82 \mathrm{~nm}$ for $5 \%$ Al concentration. Micro strain and dislocation density increases with decrease in Al content. Lattice constants 'a' and 'c' well matches with the standard value.

\section{Morphological studies}

The FESEM images of different Al content $\mathrm{ZnO}$ thin films are represented in Fig. 2. The Spherical shaped particles are seen for undoped, $1 \%$ and $3 \%$ of Al doped $\mathrm{ZnO}$ thin films ${ }^{17}$. Higher concentration of $5 \%$ Al doped $\mathrm{ZnO}$ thin film shows the large variance in the grains and splitting of spherical shape to rod shape (Fig. 2d). The particulate grain almost covers the substrate surface more or less evenly. It is seen that the morphology of $\mathrm{ZnO}$ thin films is strongly

\begin{tabular}{|c|c|c|c|c|c|c|c|c|}
\hline \multirow[t]{2}{*}{$\begin{array}{l}\text { Thin Film } \\
\text { Sample }\end{array}$} & \multirow[t]{2}{*}{$2 \theta$ (deg) } & \multirow{2}{*}{$\begin{array}{c}\text { (002) inter } \\
\text { planer d-spacing } \\
\text { distance }\end{array}$} & \multirow{2}{*}{$\begin{array}{c}\text { FWHM } \\
\text { (radians) }\end{array}$} & \multirow{2}{*}{$\begin{array}{l}\text { Crystalline } \\
\text { size } \\
\text { (D) }\end{array}$} & \multirow{2}{*}{$\begin{array}{c}\text { Dislocation } \\
\text { Density } \\
(\delta)\end{array}$} & \multirow{2}{*}{$\begin{array}{c}\text { Micro } \\
\text { strain }(\varepsilon) \\
\left(\text { lines }^{-2} \mathrm{~m}^{-4}\right)\end{array}$} & \multicolumn{2}{|c|}{$\begin{array}{c}\text { Lattice } \\
\text { parameters }\left(\mathrm{A}^{\circ}\right)\end{array}$} \\
\hline & & & & & & & a & C \\
\hline $\begin{array}{l}\text { Undoped } \\
\mathrm{ZnO}\end{array}$ & & & & & & & 3.2495 & 5.2082 \\
\hline $\mathrm{Al}$ at $1 \%$ & & & & & & 0.002221 & 3.2399 & 5.186 \\
\hline Al at $3 \%$ & 34.597 & 2 & 0.4656 & 18.66 & 2.8705 & 0.00194 & 3.2389 & 5.1849 \\
\hline Al at $5 \%$ & 34.5831 & 2.59156 & 0.4384 & 19.82 & 2.54505 & 0.001826 & 3.24 & 5.1871 \\
\hline
\end{tabular}
influenced by aluminium doping.

Table 1: Structural parameters of $\mathrm{ZnO}$ thin films for undoped, $1 \%, 3 \%$ and $5 \% \mathrm{Al}$ content
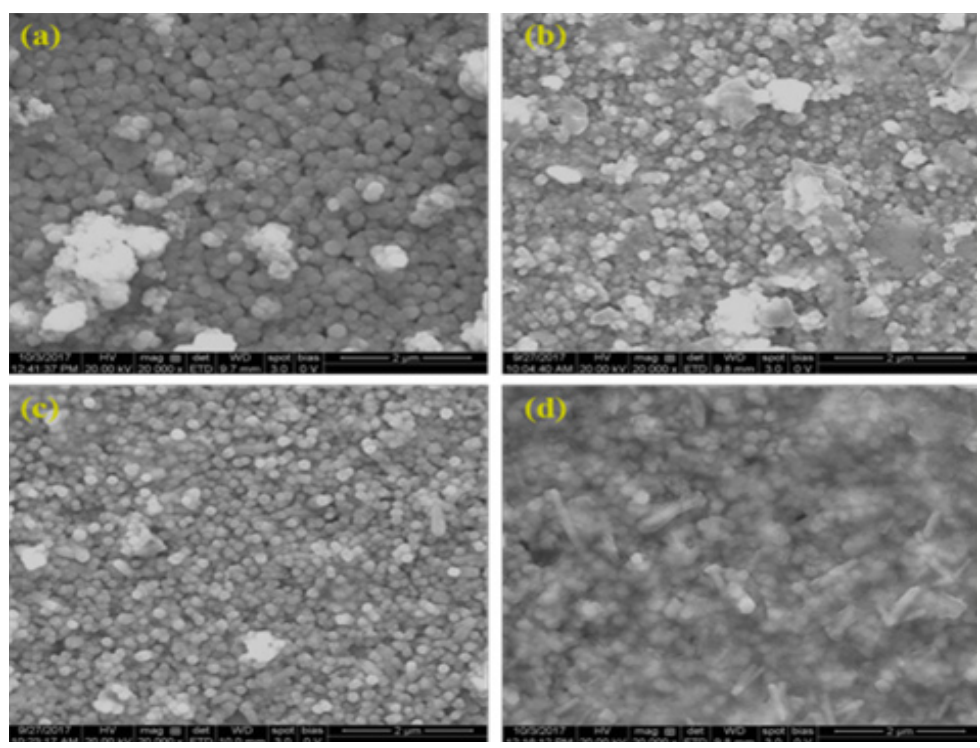

Fig.2. FESEM image of ZnO thin films (a) Undoped, (b) $1 \% \mathrm{Al}$ (c) $3 \% \mathrm{Al}$ and (d) $5 \% \mathrm{Al}$ 
The EDAX spectrum of undoped and $5 \%$ Aluminium doped $\mathrm{ZnO}$ thin films are shown in the Fig. 3(a) and 3(b). It confirms $\mathrm{Zn}, \mathrm{O}$ and $\mathrm{Al}$ are

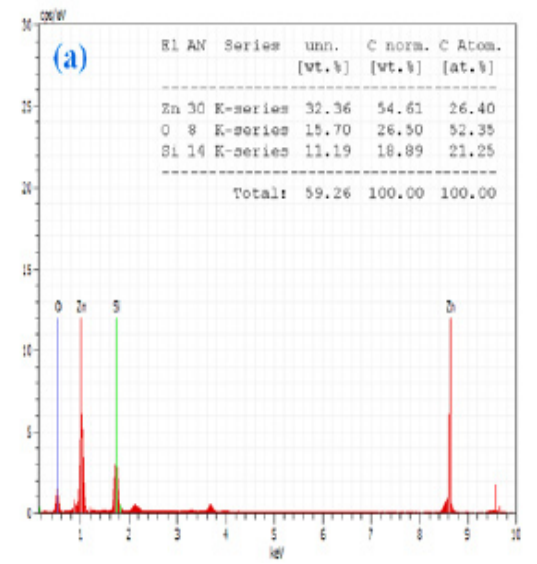

Fig. 3. EDAX spectrum of ZnO thin films (a) Undoped (b) $5 \%$ Al doped

\section{Optical Studies}

Figure 4 (a) shows the UV absorption spectrum of $\mathrm{ZnO}$ thin films for undoped and Aluminium doped thin films in the wavelength region $200 \mathrm{~nm}$ to $1400 \mathrm{~nm}$. It shows that minimum absorption seen in $1 \% \mathrm{Al}$ doped $\mathrm{ZnO}$ thin film and the maximum absorbance is seen in 5\% $\mathrm{Al}$ doped $\mathrm{ZnO}$ film. The doping of $\mathrm{Al}$, affects the density of unsaturated bonds causing variation of local states in the band gap and this might be the cause for changes in absorption.

Figure 4 (b) shows the relation between

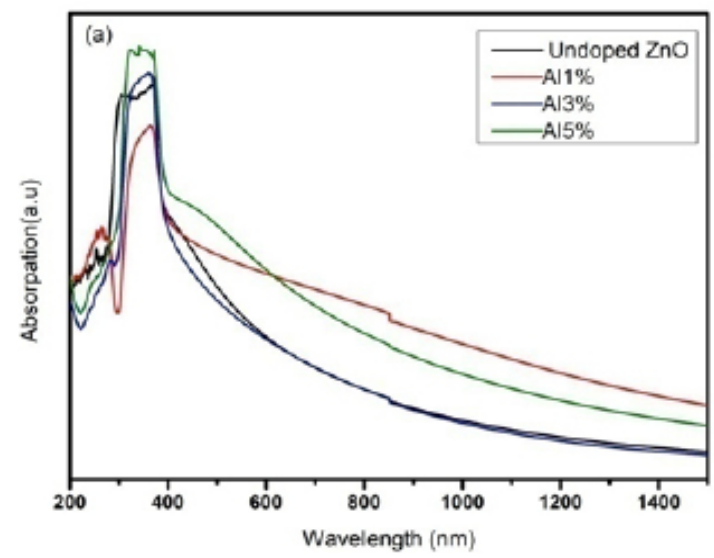

present in the prepared film. The atomic percentages of the elements present are given in the insert table of Figure 3.

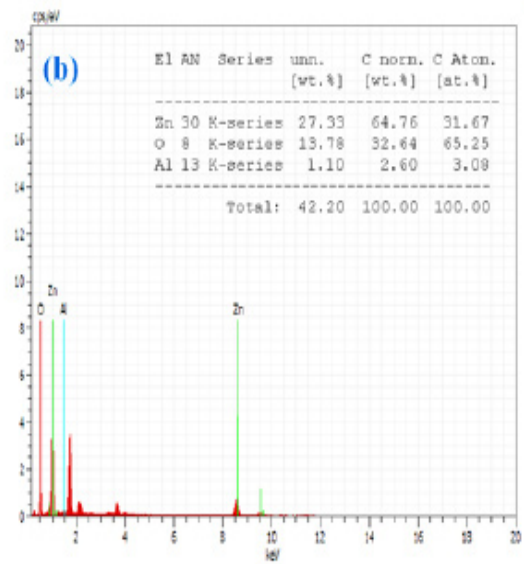

( $\alpha$ hu)2 and (hu) for undoped and Aluminium doped $\mathrm{ZnO}$ thin films. The band gap is obtained from the straight line region of ( $\alpha$ hu) 2 versus hu and the band gap energy of undoped, $1 \%, 3 \%$ and $5 \%$ Aluminium doped $\mathrm{ZnO}$ thin films are $3.55 \mathrm{eV}, 3.68 \mathrm{eV}, 3.82 \mathrm{eV}$ and $3.25 \mathrm{eV}$ respectively. Fig. 4 (b) shows that the band gaps initially widened with increasing aluminium content up to $3 \%$ and then the absorption edge shifted again to longer wavelength range ${ }^{18}$. This red shift is clarified by stress relaxation mechanism. This is because impurity band merges into conduction band causing the reduction in the band gap ${ }^{19}$.

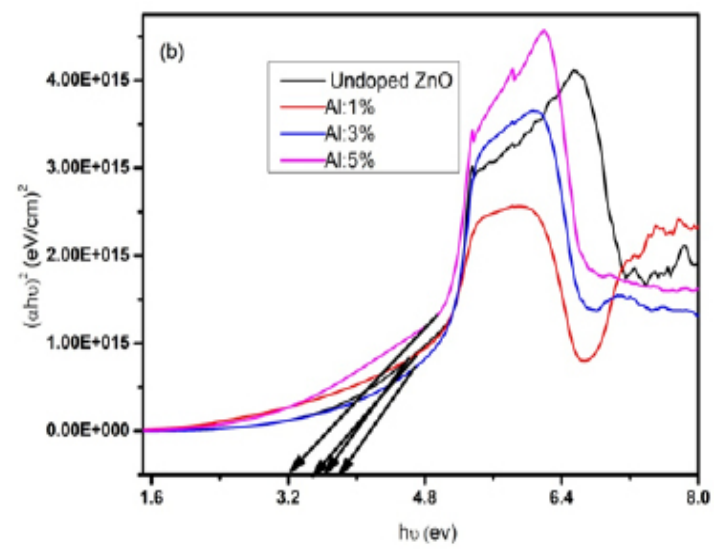

Fig. 4. (a) UV Absorption spectrum (b) Optical Band gap

Figure 5 shows the undoped and Al doped ZnO films PL spectrum for wavelength ranging from $300 \mathrm{~nm}$ to $550 \mathrm{~nm}$ under the excitation of $325 \mathrm{~nm}$. With increase in the Al doping concentration, the intensity of peak increases with a decrease in peak broadening ${ }^{20}$. The emission spectrum shows two peaks. The strong band emission peak obtained near $381 \mathrm{~nm}$ relates to near band edge 
emission of $\mathrm{ZnO}$, the UV emission due to near band edge emission which can be connected to free excitation recombination. The weak band emission peak obtained near $500 \mathrm{~nm}$ corresponds to green emission peaks associated with deep level emission. The green emission of undoped $\mathrm{ZnO}$ has negligible visible peak intensity and as the Al doping content increases the intensity also gets increased. The $\mathrm{Al}^{3+}$ ions can get into the $\mathrm{ZnO}$ structures by making oxygen vacancies or incorporating into holes, many of the $\mathrm{Al}^{3+}$ are substituted at low doping concentration and the additional $\mathrm{Al}^{3+}$ incorporate into the gaps of $\mathrm{ZnO}$ nano particles at the higher concentration making large amount of lattice defects. The blue green emission peaks are at around $447 \mathrm{~nm}$ to $549 \mathrm{~nm}$ by the energy transmission of electrons ${ }^{21}$.

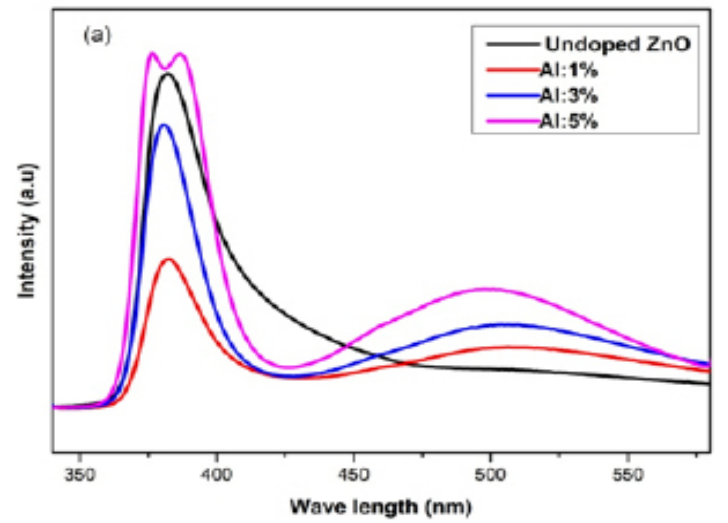

Fig. 5. Undoped and Al doped ZnO Thin Films PL Spectrum

\section{CONCLUSION}

$\mathrm{ZnO}$ thin films are coated on glass substrate for undoped, $1 \%, 3 \%$ and $5 \% \mathrm{Al}$ content by dip coating method. XRD studies show that the prepared $\mathrm{Al}-\mathrm{ZnO}$ thin films are polycrystalline nature by Wurtzite hexagonal structure. The crystalline size of the Al doped $\mathrm{ZnO}$ films is smaller when matched with undoped $\mathrm{ZnO}$ film. By increasing the Al content the crystalline size of the $\mathrm{Al}$ doped $\mathrm{ZnO}$ thin films get increased. The FESEM analysis shows the spherical growth of undoped and $\mathrm{Al}$ doped $\mathrm{ZnO}$ thin films. It also shows that surface morphology is strongly disturbed by Al doping. The EDAX result shows the existence of $\mathrm{Zn}, \mathrm{O}$ and $\mathrm{Al}$ elements in the thin films. UV-Vis spectrum shows that least absorbance appears for $1 \% \mathrm{Al}$ content in the visible region. The band gap for undoped, $1 \%, 3 \%$ and $5 \% \mathrm{Al}$ doped $\mathrm{ZnO}$ are $3.55 \mathrm{eV}, 3.68 \mathrm{eV}, 3.82 \mathrm{eV}$ and $3.25 \mathrm{eV}$ respectively. Near band emission in the $\mathrm{PL}$ spectrum indicates the appearance of interstitial $\mathrm{Zn}^{+}$ ions and deep level emission confirms the oxygen ion vacancy.

\section{ACKNOWLEDGEMENT}

We are thankful to the Department of Electronics, PSG College of Arts \& Science for providing the lab facilities to do our research work and also for taking studies.

\section{REFERENCES}

1. Song, J.; Zhou, J.; Wang, A.L.; Nano Lett., 2006, 6, 1656.

2. Jeong, I.S.; Kim, J.H.; Im, S.; Appl. Phys. Lett., 2003, 83, 2946.

3. Zhang, Z.Z.; Lu, Y.M.; Shen, D.Z.; Zhang, J.Y.; Li, B.H.; Zhao, D.X.; Fan, X.W.; Tang, K.; Appl. Phys. Lett., 2006, 88, 031911.

4. Ozgur, U.; AlivovYa, I.; Liu, C.; Teke, A.; Reshchikov, M. A.; Dogan, S.; Avrutin, V.; Cho, S. J.; Morkoc, H. Journal of Applied Physics., 2005, 98, 041301

5. Hyun, H.M.; Hong, K.; Kim, B.H.; J. Korean Ceram. Soc., 1996, 33, 149-154.

6. Majumder, S.B.; Jain, M.; Dobal, P.S.; Katiyar, R.S.; Mater. Sci. Eng., B 2003, 103, 16-25.
7. Li, Q.W.; Bain, J.M.; Sun, J.C.; Wang, J.W.; Luo, Y.M.; Sun, K.T.;Yu, D.Q.; Appl. Surf. Sci., 2010, 256, 1698.

8. Boukhenoufa, N.; Mahamdi, R.; Rechem, D. Semicond., 2016, 37, 113001

9. Meyer, J.; Kidambi, P.R.; Bayer, B.C.;Weijtens, C.; Kuhn, A.; Centeno, A.; Pesquera, A.; Zurutuza, A.; Robertson, J. Sci. Rep., 2014, 4, 5380.

10. Prasad, A.K.; Kubinski, D.J. Gouma, P.I.; Sens. Actuators., B 2003, 93, 25.

11. Yordanov, R.; Boyadjiev, S.; Georgieva, V.; Vergov, L. J. Phys. Conf. Ser., 2014, 514, 012040. 
12. Yordanov, R.; Boyadjiev, S.; Georgieva, V.; Vergov, L. J. Phys. Conf. Ser., 2014, 514, 012040.

13. Altman, E.I.; Droubay, T.; Chambers, S.A. Thin Solid Films., 2002, 414, 205.

14. Patterson, A. L. Phys, Rev., 1939, 56, 978.

15. Suresh, R.; Ponnusamy, V.; Mariappan, R.; Senthil Kumar, N. Ceram. Int., 2014, 40, 437 $-445$

16. Marnadu, R.; Chandrasekaran, J.; Raja, M.; Balaji, M. Journal of material sci. Material in Electronics., 2017, 1-10.

17. Manjeet Kumar,; Bikmramjeet Singh,; PankajYadav,; Vishwa Bhatt,; Manoj
Kumar,; Kulwinder Singh,; Abhyankar, A.C.; Akshay Kumar,; Ju-Hyung Yun. Ceramics International., 2017, 43, 3562 - 3568.

18. Mondal, S.; Bhattacharyya, S.R.; Mitra, P. J Phys., 2013, 80, 315-326.

19. Mohanty, B.C.; Jo, Y.H.; Yeon, D.H.; Choi, I. J.; Cho, Y. S. Appl. Phys. Lett., 2009, 95, 62103.

20. Mahadik, M.A.; Hunge, Y.M.; Shinde, S.S.; Rajpure, K.Y.; Bhosale, C. H. J. of Semiconductors., 2005, 36, 033002.

21. Xu, P.S.; Sun, Y.M.; Shi, C.S.; Xu, F.Q.; Pan, H. B. Nuclear Inst. Methods in Phys. Rese., Sect., B. 2003, 199, 286. 